Open Access

\title{
Assessing the effect of giving and receiving written corrective feedback on improving L2 writing accuracy: does giving and receiving feedback have fair mutual benefit?
}

\author{
Afsar Rouhi ${ }^{1}$, Minou Dibah ${ }^{2}$ and Hassan Mohebbi ${ }^{3,4^{*}}$ (D)
}

\author{
* Correspondence: hassan. \\ mohebbi973@gmail.com \\ 3SAM Language Institute, Ardabil, \\ Iran \\ ${ }^{4}$ European knowledge \\ Development Institute, Ankara, \\ Turkey \\ Full list of author information is \\ available at the end of the article
}

\begin{abstract}
Although the findings of second language $(L 2)$ studies conducted to date have provided evidence for the positive effect of written corrective feedback (hereafter feedback) on improving L2 learners' writing grammatical accuracy, there is no conclusive evidence regarding which kind of feedback is more beneficial for enhancing L2 writing. This study compares the differential effects of giving and receiving unfocused direct feedback on improving Iranian EFL learners' writing accuracy. To this end, 61 learners of English were randomly assigned to three groups, including a feedback giver group ( $n=19)$, a feedback receiver group $(n=22)$, and a control group $(n=20)$. The participating groups took Cambridge English Preliminary Test (PET), completed four translation tasks as the treatment, and took two tests, namely a translation test and a picture description test. The data analysis indicated the effectiveness of the feedback provided by peers. Additionally, further data analysis revealed that the participants in the feedback giver group outperformed the participants in the feedback receiver and the control groups in translation and picture description tests, underscoring the positive effect of giving feedback on learners themselves rather than learners who receive feedback. The findings and potential pedagogical implications of the study are discussed in detail.

Keywords: Written corrective feedback, Feedback giver, Feedback receiver, Peer feedback, Teacher feedback, Involvement load hypothesis
\end{abstract}

\section{Introduction}

The issue of providing written corrective feedback (hereafter feedback) has been an ongoing debate in second language acquisition (SLA) for almost three decades (for a review, study Reinders \& Mohebbi, 2018). Yet, there is still no conclusive evidence concerning the efficacy of specific feedback strategies in improving second language (L2) learners' writing accuracy. L2 researchers, to date, have investigated the effect of feedback on L2 learners' writing ability from different perspectives, including focused

(c) The Author(s). 2020 Open Access This article is licensed under a Creative Commons Attribution 4.0 International License, which permits use, sharing, adaptation, distribution and reproduction in any medium or format, as long as you give appropriate credit to the original author(s) and the source, provide a link to the Creative Commons licence, and indicate if changes were made. The images or other third party material in this article are included in the article's Creative Commons licence, unless indicated otherwise in a credit line to the material. If material is not included in the article's Creative Commons licence and your intended use is not permitted by statutory regulation or exceeds the permitted use, you will need to obtain permission directly from the copyright holder. To view a copy of this licence, visit http://creativecommons.org/licenses/by/4.0/. 
and unfocused feedback (e.g., Bitchener \& Knoch, 2009; Nemati, Alavi, \& Mohebbi, 2019), direct and indirect feedback (Karim \& Endley, 2019; Kim \& Bowles, 2019), the feedback medium (Zhang, 2020), L2 learners and teachers' perceptions, preferences, needs, and practices in writing tasks (Bahrouni \& Tuzlukova, 2019; Motallebzadeh, Kondori, \& Kazemi, 2020; Nemati, Alavi, Mohebbi, \& Masjedlou, 2017; Raza, 2019), and the source of feedback, namely teacher and/or peer (Ferris, 1995; Hyland, 2000; Miao, Badger, \& Zhen, 2006; Peterson \& Portier, 2014; Zhang \& McEneaney, 2020). These studies and their inconclusive and somehow contradictory findings have given rise to a great deal of discussion on the value of feedback in developing writing accuracy. Surprisingly enough, despite the importance attached to the L2 learners' active role in L2 learning, little research has examined the potential positive effect of learners' active role in the form of correcting their peers' writing in L2 writing pedagogy.

The experimental studies conducted to date have yielded contradictory results regarding the impact of peer feedback compared to teacher corrective feedback (hereafter teacher feedback). Evidently, there is a gap in the literature concerning the effect of peer feedback, in particular, the potential benefit of giving feedback for the learners themselves rather than their peers. Therefore, this study might shed some light on the effects of peer feedback on enhancing L2 learners' ability to write more accurately, especially for the learners who give peer feedback.

In the next section of the article, we outline the arguments for and against the teacher and peer feedback and review the most recent research investigating the effect of these feedback strategies on improving the accuracy of L2 learners' writing.

\section{The arguments for and against teacher and peer feedback}

There have been many arguments for and against the efficacy of teacher and peer feedback on L2 writing. Despite the importance attached to teacher feedback, L2 research findings cast doubt on the perceived effect of teacher feedback on prompting L2 writing (Ferris, 1995). It is argued that teacher feedback might have detrimental effects on L2 learners' writing (Hyland, 2000).

When a learner receives teacher feedback, they are usually expected to include all points provided by the teacher from A to Z. This degree of authority runs the risk of undermining the authenticity of the writing task (Berg, 1999), leaving no choice for learners in revising the composition (Muncie, 2000). Reliance on teacher feedback might deprive learners of taking responsibility for their writing tasks (Lee, 2009), which is in sharp contrast with the tenets of fostering learner autonomy. With such a profile, teacher feedback might not seem to serve any promising purpose with respect to L2 writing (Kozlova, 2010). Mahfoodh (2017) investigated learners' emotional responses to teacher feedback. The results showed that the students felt frustrated after receiving teacher feedback. Some students were in favor of the teacher's feedback, while others rejected it, some expressed satisfaction and some were dissatisfied with teacher feedback.

Unlike teacher feedback, peer feedback can help L2 learners build skills that can be transferred to their editing tasks and enhance their confidence in L2 writing (Byrd, 2003). The emerging process-oriented approach to L2 writing stresses the value of peer 
feedback in improving L2 writing (Moon, 2008). Process writing theory, collaborative learning theory, interactionist theory, and sociocultural theory supports peer feedback (Yu \& Lee, 2016). Peer feedback may have the potential to provide invaluable opportunities for L2 learners to negotiate meaning; such feedback might create a facilitative socio-interactive environment in which L2 learners are encouraged to scaffold each other; and it might foster autonomy making L2 learners less dependent on the teacher (Hu, 2005; Hu \& Lam, 2010).

Indeed, peer feedback can give the feedback receiver the option of casting doubt on the feedback provided, analyzing it against their knowledge, and discarding the feedback in their writing (Berg, 1999). L2 learners should experience learning opportunities through peer feedback, which might not be easily gained from teacher feedback (Berg, 1999). Likewise, peer feedback may reduce L2 learners' writing apprehension and may be beneficial for reviewers as well as writers (Chaudron, 1984). Lundstorm and Baker (2009) claimed that peer feedback is helpful to L2 learners who give feedback because such learners become familiar with more global aspects of good writing and gain useful experience in critical reading of a manuscript. It also seems likely that peer feedback might help L2 learners come up with an evaluative checklist in providing feedback that might be taken into account in feedback givers' manuscripts as well.

Similarly, peer feedback may help L2 learners develop general writing skills and enable them to self-evaluate their compositions. Hyland (2010) urged L2 teachers to view L2 learners as active participants in L2 writing through employing peer feedback, which involves receiving feedback, giving feedback, analyzing peer feedback, and deciding whether to include peer feedback or not. She claimed that active student participation and engagement are of overriding importance in L2 writing pedagogy if the L2 learning potential of feedback is to be fully achieved. Keen (2010) encouraged L2 teachers to take advantage of implicit learning through engaging learners in peer feedback, which has the potential to help learners internalize effective strategies, techniques, and structures that can be activated in their own writing. Miao et al. (2006) found that most of the teacher feedback and more than half of peer feedback was involved in the revised drafts of the learners. Interestingly, peer feedback led to meaning-changes while teacher feedback resulted in changes in the surface level.

On the other hand, some issues have been raised which might overshadow the effectiveness of peer feedback in improving the writing accuracy of L2 learners, in particular the need for training learners, structuring and monitoring the peer feedback sessions, potential problems about social roles and cross-cultural dynamics within pairs or groups in peer feedback, and the need for an appropriate balance between peer feedback, teacher peer feedback, self-editing, and other sources (Ferris, 2003). As Chong (2017) observed, there is a strong and positive relationship between learners' writing proficiency and the quality of feedback they give on their peers' writing. In a recent study, Sánchez-Naranjo (2019) reported a positive effect of peer review, especially the role of training learners to give feedback on enhancing text quality.

When an L2 learner gives feedback, they are only able to provide feedback on a certain number of errors already mastered (Kozlova, 2010). Likewise, L2 learners focus 
mainly on surface aspects of writing and turn a blind eye to more important revising concerns like semantic or textual ones; they provide ambiguous feedback; and they take a critical and biased stance towards their peer's composition (Liu \& Sadler, 2003). Similarly, Diab (2010) pointed out that peer feedback might not be as useful as expected because L2 learners might not be able to indicate the errors in their peer's compositions, may not trust their peer's WCF, and might be mainly inclined towards TWCF.

To date, L2 researchers (e.g., Liu \& Sadler, 2003; Ma, 2010; Miao et al., 2006; Min, 2006; Nelson \& Carson, 1998; Paulus, 1999; Peterson \& McClay, 2010; Suzuki, 2008; Tsui \& Ng, 2000; Villamil \& De Guerrero, 1996, 1998; Wigglesworth \& Storch, 2009; Zhu, 2001) have examined different aspects of peer feedback in improving L2 writing. The studies conducted so far have reported mixed findings with regard to the effectiveness of peer feedback in improving L2 learners' writing accuracy. Two recent studies provided evidence for the effect of peer feedback: Wu and Schunn (2020) investigated the relationship between peer feedback features, student perceptions and the potential chance of implementing the feedback and provided support for the effectiveness of peer feedback. Pham, Huyen, and Nguyen (2020) reported an 11-week case study inquiring into the effect of the trained peer feedback of 92 English-major students. They concluded the positive impact of peer feedback on revising their writing. However, these are two studies in different contexts which makes the findings less comparative and conclusive. Evidently, what we need is more research projects investigating this issue in various educational contexts.

\section{The study}

The studies conducted to date in this field have yielded conflicting findings. Lee (2011) underscored the fact that although teacher feedback is a dominant technique in writing pedagogy and L2 learners rely more and more on their teachers' comments, their writing does not improve significantly as a result of teacher feedback. In contrast, Peterson and Portier (2014) reported an advantage for peer feedback. They observed that the learners gave feedback on the content and conventions in their peers' writing. They concluded that 'Written compositions improved and writing development was enhanced through the giving and receiving of peer feedback" (p. 20). As a result, our study may extend the research on the efficacy of giving and receiving feedback on the writing accuracy of L2 learners in an EFL context in Iran.

\section{Research question}

The following main research question guided the present study:

Is there any significant difference between peer feedback giver and receiver groups in terms of writing accuracy?

\section{Method}

\section{Participants}

Sixty-one Iranian learners of English (male and female, ranging in age from 18 to 21) from two state universities participated in this study. They were first and 
second-year university students majoring in Translation Studies and English Language Teaching (ELT). The participants had Azari-Turkish as their first language and Persian as a formal language of instruction in Iran. The participants were randomly divided into three groups, namely a feedback giver group $(n=19)$, a feedback receiver group $(n=22)$, and a control group $(n=20)$. The homogeneity of the participating groups in terms of L2 proficiency was assured through Cambridge English Preliminary Test (PET).

\section{Instruments}

\section{Proficiency test}

To get assurance as to the homogeneity of the participating groups in terms of L2 proficiency, the participants took PET. The test has four main sections: reading, writing, listening, and speaking. In this study, we excluded the listening section as it was irrelevant to the present study. Total marks for reading, writing, listening, and speaking components are 25, 25, 25, and 25. PET has two cut-scores, pass and pass with merit. Those who get 70 pass the test and are judged to be at an intermediate level of proficiency.

\section{Translation tasks}

We chose translation task because this task, similar to tasks based on visual materials such as picture description task, assesses only writing, not the content knowledge that is assessed in argumentative writing tasks (Hughes, 2003). Also, this task provides an obligatory context for learners to produce the targeted structure(s). We selected five reading texts from the Active Reading 2 book. The readability indices of the texts were computed by readability software 1.0 and the Flesch-Kincaid readability (FKRT). The FKRT readability indices calculated for text 1 , text 2, text 3, text 4 , and text 5 appeared to be 57 (Grade 9), 56 (Grade 9), 51 (Grade 10), 48 (Grade 10), and 42 (Grade 11), respectively. In the Flesch-Kincaid readability test, the higher numbers (90.5-100.0) imply that the passages are easier to read, and lower numbers (0-30) mark passages that are more difficult to read. The numbers given in parentheses stand for the readability of the passages. The indices computed revealed that the passages were appropriate for the participants of the study.

The selected passages were translated into Persian. To get assurance as to the reliability of the translations, two of our colleagues checked the translations. Additionally, a list of keywords for each passage was given in English. Four passages were used in the treatment sessions.

\section{Posttests}

To examine the effect of different levels of the independent variable, i.e., giving and receiving peer feedback on the participants' L2 writing accuracy, they were asked to translate a text from Persian into English and perform a picture description task. In this

Table 1 Levene's test for the proficiency test

\begin{tabular}{lccr}
\hline Levene's statistic & $\mathrm{df1}$ & $\mathrm{df2}$ & Sig. \\
\hline .84 & 2 & 58 & .43
\end{tabular}


Table 2 ANOVA results for the proficiency test

\begin{tabular}{lllcll}
\hline Source & Sum of Squares & df & Mean Square & F & Sig. \\
\hline Between Groups & 284.59 & 2 & 142.29 & 2.812 & .068 \\
Within Groups & 2935.35 & 58 & 50.61 & & \\
Total & 3219.95 & 60 & & & \\
\hline
\end{tabular}

task, a series of five pictures were provided which depicted a story. The participants were required to narrate the story in 150 words or more.

\section{Procedures}

Before the main study, we conducted a pilot study to figure out any potential problem in the data collection procedure and the designed tasks and also come up with the time which participants needed to complete the tasks. Based on the findings of the pilot study, the tasks were adapted, and the time of task completion was set as $30 \mathrm{~min}$.

On the day before the treatment sessions of the main study started, the participants took the PET. They proved to be homogeneous in terms of second language proficiency, $F(2,58)=2.81, p=.068$. Then, they were randomly assigned to three groups, namely a feedback giver group, a feedback receiver group, and a control group. They completed the translation tasks for four sessions. After completing the first task, the feedback giver group provided feedback on the manuscripts of the feedback receiver group. The participants in the feedback giver group could use a dictionary in commenting on the manuscripts. At the beginning of the second session, the participants in the feedback receiver group were offered the chance of reviewing the comments given by the feedback giver group and revising their writing with the comments incorporated. Then, they completed the second translation task. For four sessions, the feedback giver group completed their translation tasks and provided feedback on the manuscripts' of participants in the feedback receiver group. In fact, the participants in the feedback giver group provided direct unfocused feedback by providing the correct form of all errors. Likewise, the feedback receiver group was required to review the feedback provided on their previous manuscripts, reflect on them, and complete a new translation task. The participants in the control group only completed the translation tasks without providing or receiving any feedback. When the treatment sessions were over, all participant groups took a translation task, as a testing instrument. After 2 weeks, they completed a picture description task, as the second testing instrument, to assess the effect of treatment conditions on a different task.

Table 3 Descriptive statistics for the translation task

\begin{tabular}{lllll}
\hline Groups & N & Mean & SD & Std. Error \\
\hline Feedback Giver & 19 & 72.06 & 17.35 & 3.98 \\
Feedback Receiver & 22 & 50.58 & 22.39 & 4.77 \\
Control & 20 & 46.19 & 22.31 & 4.98 \\
Total & 61 & 55.83 & 23.41 & 2.99 \\
\hline
\end{tabular}


Table 4 ANOVA results for the translation task

\begin{tabular}{lllcll}
\hline Source & Sum of Squares & df & Mean Square & F & Sig. \\
\hline Between Groups & 7471.30 & 2 & 3735.65 & 8.52 & .001 \\
Within Groups & $25,418.50$ & 58 & 438.25 & & \\
Total & $32,889.80$ & 60 & & & \\
\hline
\end{tabular}

Every single participant's writing was coded for the number of clauses and error-free clauses. Following Foster and Skehan (1996), the accuracy of L2 writing was measured by calculating the number of error-free clauses as a percentage of the total number of clauses. The rater who was one of our colleagues who had 10 years of teaching experience corrected the manuscripts, and the number of error-free clauses was divided by the total number of clauses in each manuscript and was multiplied by 100 . One-third of the manuscripts in each task was randomly scored by another rater to ensure interrater reliability. The inter-rater reliability for the translation task and the picture description task were .95 and 1 , respectively.

\section{Results}

\section{Cambridge English preliminary test}

As already mentioned, PET was used to check the homogeneity of the participating groups. The data obtained were submitted to SPSS for running statistical analyses. Firstly, the Levene's test of equality of error variances was run to check whether the ANOVA could be run or not. The results of the Levene's test of equality of error variances, $p=.43$, indicated that ANOVA could be used. Table 1 shows the results of the Levene's test of equality of error variances for the proficiency test.

Secondly, an ANOVA was run to ensure the homogeneity of the participating groups. The results of the ANOVA run revealed that there was no statistically significant difference among the three participating groups in terms of L2 proficiency. Table 2 shows the ANOVA results for the proficiency test.

\section{Translation task}

The first testing instrument which was used to examine the effectiveness of different conditions of the study was the translation task. The data obtained was put into SPSS and a One-way ANOVA was run. Table 3 shows the descriptive statistics for the translation task, and Table 4 presents the results of the ANOVA run for the translation task.

Table 5 Post-hoc Analysis (LSD test) for the translation task

\begin{tabular}{|c|c|c|c|c|c|}
\hline \multirow[t]{2}{*}{ Group 1 vs. Group 2} & \multirow{2}{*}{$\begin{array}{l}\text { Mean } \\
\text { Difference }\end{array}$} & \multirow{2}{*}{$\begin{array}{l}\text { Std. } \\
\text { Error }\end{array}$} & \multirow[t]{2}{*}{ Sig. } & \multirow{2}{*}{$\begin{array}{l}\text { 95\% Confidence } \\
\text { Lower Bound }\end{array}$} & \multirow{2}{*}{$\begin{array}{l}\text { Interval } \\
\text { Upper Bound }\end{array}$} \\
\hline & & & & & \\
\hline Feedback Givers vs. Feedback Receivers & 21.48 & 6.55 & .002 & 8.36 & 34.60 \\
\hline Feedback Givers vs. Control & 25.87 & 6.70 & .000 & 12.4 & 39.29 \\
\hline Feedback Receivers vs. Control & 4.38 & 6.46 & .500 & -8.5 & 17.33 \\
\hline
\end{tabular}


Table 6 Kruskal-Wallis H Test for the picture description task

\begin{tabular}{lll}
\hline Groups & $\mathrm{n}$ & Mean Rank \\
\hline Feedback Giver & 19 & 43.87 \\
Feedback Receiver & 22 & 32.73 \\
Control & 20 & 16.88 \\
Total & 61 & \\
\hline
\end{tabular}

As Table 3 presents, the mean for the feedback giver group $(M=72.06)$ is higher than the mean for the feedback receiver group $(M=50.58)$, which in turn is higher than the mean for the control group $(M=46.19)$.

The difference across the participating groups reached significance, $F=8.52, p=$. 001. The values observed for the $F$ and $p$ indicated that the three groups involved did not perform equally in the translation task because of the different conditions to which they were exposed during the treatment period (Table 4).

To statistically determine where the significant differences lay between the participating groups, a post-hoc (LSD) test was also run. As Table 5 represents, there was a statistically significant difference between the feedback giver group and the feedback receiver group, in favor of the feedback giver group, $p=.002$. Likewise, the difference between the feedback giver group and the control group reached statistical significance in favor of the feedback giver group, $p=.001$. However, the difference between the feedback receiver group and the control group did not reach statistical significance, $p=.50$.

In brief, the data analysis revealed that the participants in the feedback giver group outperformed the participants in the feedback receiver group and the control group in the translation task. Although the difference between the feedback receiver group and the control group was not significant, the descriptive data showed that the participants in the feedback receiver group performed better than the participants in the control group in the translation task.

\section{Picture description task}

In the second task, the members of the participating groups were required to narrate a story based on a sequence of pictures given to them. Since the Levene's test for equality of error variances appeared to be significant, $p=.001$, the non-parametric alternative to ANOVA, i.e., the Kruskal-Wallis H Test was run for the picture description task. Table 4 shows the results of the Kruskal-Wallis $\mathrm{H}$ Test for the picture description task.

As it is clear in Table 6, the feedback giver group obtained the highest overall mean rank, the control group did the lowest, and the feedback receiver group ranked in between.

Table 7 Test statistics for the picture description task

\begin{tabular}{lc}
\hline Chi-Square & 22.91 \\
\hline $\mathrm{df}$ & 2 \\
Asymp. Sig. & .000 \\
\hline
\end{tabular}


Table 8 Feedback giver group and feedback receiver group ranks in the picture description task

\begin{tabular}{llll}
\hline Groups & N & Mean Rank & Sum of Ranks \\
\hline Feedback Giver & 19 & 26.05 & 495.00 \\
Feedback Receiver & 22 & 16.64 & 366.00 \\
\hline
\end{tabular}

The output presented in Table 7 for the Kruskal-Wallis H Test demonstrated that there was a statistically significant difference in feedback across the three groups involved in the present study (Gp1, $n=19: \mathrm{Gp} 2, n=22$ :, Gp3, $n=20), x^{2}(2, n=61)=$ $22.91, p<.001$.

The feedback giver group obtained a higher median score $(\mathrm{Md}=95.65)$ than the feedback receiver and control groups, which recorded median values of 75.00 and 36.67, respectively. Since the difference across the three groups reached statistical significance in the Kruskal-Wallis H Test, there was a need to carry out three follow-ups MannWhitney $\mathrm{U}$ tests between pairs of groups (i.e., between the feedback giver group and the feedback receiver group, the feedback giver group and the control group, and the feedback receiver group and the control group) to locate the exact difference among the three groups of participants.

To control Type I errors, a Bonferroni adjustment was applied to the alpha values (i.e., $.05 \div 3=.0167)$. The descriptive statistics for the Mann-Whitney $U$ for the feedback giver group and feedback receiver group were presented in Table 8. As it is shown, the mean rank for the first group $(M R=26.05)$ was higher than the mean rank for the second group $(M R=16.64)$.

The Mann-Whitney $U$ run for the feedback giver group and feedback receiver group showed that there was a statistically significant difference between these two groups ( $\mathrm{Md}=95.65, n=19, \mathrm{Md}=75.00, n=20), \mathrm{U}=113, \mathrm{z}=-2.51, p=.1012$ (Table 9).

Considering the pieces of information presented in Tables 8 and 9, it can be claimed that the feedback giver group outperformed the feedback receiver group significantly in the picture description task.

The second Mann-Whitney $U$ was run between the feedback giver group and the control group. The descriptive statistics presented in Table 10 demonstrated that the mean rank for the feedback receiver group $(M R=27.82)$ was higher than the mean rank for the control group ( $M R=12.58)$.

The test also showed that there was statistically significant difference between these two groups too ( $\mathrm{Md}=95.65, n=19, \mathrm{Md}=36.07, n=22), \mathrm{U}=41.50, \mathrm{z}=-4.18, p=.001$ (Tables 9, 11 and 12).

The descriptive data gained from the third Mann-Whitney U run revealed that the mean rank for the feedback receiver group ( $M R=27.59)$ was higher than the control group $(M R=14.80)$. As it is clear in Table 13 , there was statistically significant

Table 9 Test statistics for the feedback giver group and feedback receiver group in the picture description task

\begin{tabular}{lc}
\hline Mann-Whitney U & 113.00 \\
\hline$Z$ & -2.51 \\
Asymp. Sig. (2-tailed) & .012 \\
\hline
\end{tabular}


Table 10 Feedback giver group and control group ranks in the picture description task

\begin{tabular}{llll}
\hline Groups & $\mathrm{n}$ & Mean Rank & Sum of Ranks \\
\hline Feedback Giver & 19 & 27.82 & 528.50 \\
Control & 20 & 12.58 & 251.50 \\
\hline
\end{tabular}

difference between the feedback giver group and control group $(\mathrm{Md}=95.65, n=19$, $\mathrm{Md}=36.67, n=20), \mathrm{U}=86, \mathrm{z}=-3.37, p=.001$. Simply put, the feedback receiver group outperformed the control group in describing the pictures given as the posttest.

\section{Discussion}

The present study examined the effect of giving and receiving peer feedback on L2 learners' writing accuracy in an EFL context in Iran. More specifically, it aimed to investigate whether the participants who provided feedback could take advantage of feedback more than the participants who received feedback. First, it is worth mentioning that although there has been plenty of arguments for and against feedback in the last three decades (e.g., Bitchener \& Knoch, 2010; Ferris, 2004; Truscott, 2004), the results of this study provided support for the effectiveness of feedback, namely unfocused direct feedback on improving L2 learners' ability to write accurately.

The result of the study implies the positive effect of peer feedback. Peer feedback might have the potential to enhance learner autonomy and encourage learners to take an active role in L2 learning. Peer feedback might raise learners' awareness of their strengths and weaknesses in L2 writing, help learners become familiar with global aspects of L2 writing and critical reading, foster reflection, facilitate collaborative learning and assume an active role for learners in L2 learning.

More specifically, viewed in light of the involvement load hypothesis (Hulstijn \& Laufer, 2001), it seems reasonable to argue that peer feedback engages L2 learners more in performing L2 writing tasks, which in turn leads to improved L2 writing ability. The involvement load hypothesis argues that learning is dependent on the amount of mental effort or involvement that a task imposes. Three factors play a crucial role in task-induced involvement, namely need, search, and evaluation. "Need" implies the obligation to complete the task. "Search" indicates the attempts which an L2 learner makes to resolve the task, and "evaluation" involves passing judgment about the outcome of the task. Therefore, it can be argued that the participants in the feedback giver group were engaged in a writing task that created the need to complete the task, i.e., providing the feedback, so they searched for the errors in the manuscripts, evaluated them, and finally delivered the correct form. Peer feedback might involve learners deeply in an authentic task that provides them an invaluable opportunity to read their peers' manuscripts critically, locate

Table 11 Test statistics for the feedback giver group and control group in the picture description task

\begin{tabular}{lc}
\hline Mann-Whitney U & 41.50 \\
\hline Z & -4.18 \\
Asymp. Sig. (2-tailed) & .000 \\
\hline
\end{tabular}


Table 12 Feedback receiver group and control group ranks in the picture description task

\begin{tabular}{llll}
\hline Groups & $\mathrm{n}$ & Mean Rank & Sum of Ranks \\
\hline Feedback Receiver & 22 & 27.59 & 607.00 \\
Control & 20 & 14.80 & 296.00 \\
\hline
\end{tabular}

the errors in the manuscripts, and employ their explicit knowledge to give the correct form. Then, based on the feedback provided for their peers' manuscripts, they would be able to avoid making the same errors in their manuscripts.

As the literature indicates, L2 teachers need to be encouraged to take advantage of peer feedback compared with teacher feedback. As already mentioned, teacher feedback is undermined because when L2 learners are provided with teacher feedback, they are expected to include all of the teacher feedbacks in their revised draft. In contrast, peer feedback has a positive effect on L2 writings of both the learners who provide and those who receive feedback even if they decide not to respond to all the peer feedback they receive. Furthermore, learners who provide feedback might take more advantage than learners who receive feedback. In sum, as $\mathrm{Yu}$ (2016) summarizes, we need to focus on seven issues about peer feedback: effectiveness of peer feedback compared with teacher feedback; benefits of peer feedback for givers; computer-mediated peer feedback; peer feedback training; learners' viewpoints, preferences, needs, and motives; peer interaction and group dynamics; and contextual and cultural issues. Each of these issues needs further research to provide useful guidelines and instructive suggestions for teachers to practice peer feedback in language learning classrooms. Besides, as $\mathrm{Yu}$ and $\mathrm{Hu}$ (2017) highlight, we need to consider individual differences that play a vital role in the quality of peer feedback too.

\section{Concluding remarks}

In conclusion, the findings of the present study lend support to the effectiveness of peer feedback, in particular, the unfocused direct peer feedback in enhancing the writing accuracy of L2 learners in the EFL context. Moreover, the results of this study revealed that L2 learners who provide feedback on their peer's manuscripts gain more advantages in their own L2 writing tasks than the learners who receive peer feedback. Hence, L2 teachers should be urged to give L2 learners the chance of providing feedback on their peer's manuscripts. Unfortunately, teacher feedback is the dominant strategy in writing instruction in L2 learning classrooms, in particular EFL contexts. L2 learners are given little opportunity to take a more active role in L2 learning and merely revise their manuscripts, if they are asked, and include all of the teacher feedback given without reflecting on them. In brief, it seems imperative that L2 researchers and practitioners need to conduct more studies in different language learning contexts with a

Table 13 Test statistics for the feedback receiver group and control group in the picture description task

\begin{tabular}{lc}
\hline Mann-Whitney U & 86.00 \\
\hline$Z$ & -3.37 \\
Asymp. Sig. (2-tailed) & .001 \\
\hline
\end{tabular}


more significant number of participants at different language proficiency levels, in this field and inform L2 teachers of the effectiveness of implementing peer feedback in L2 writing pedagogy. However, as Reichelt (2019) rightly argues, we do need to take into account the contextual, sociolinguistic, and educational factors in L2 writing instruction, in particular when it comes to adopting a specific feedback strategy. Also, as Sánchez-Naranjo (2019) highlights, systematic training of learners to give feedback on their partner's writing should be taken into account too.

\section{Acknowledgements}

Not applicable.

\section{Authors' contributions}

Afsar Rouhi and Hassan Mohebbi gave the idea of the paper. Minou Dibah collected the data and wrote the first draft of the paper. Afsar Rouhi did the data analysis. Hassan Mohebbi revised the paper in different stages of the study. The author(s) read and approved the final manuscript.

\section{Authors' information}

No interest.

Funding

Not applicable.

\section{Availability of data and materials}

Not applicable.

\section{Competing interests}

The authors declare that they have no competing interests.

\section{Author details}

${ }^{1}$ University of Mohaghegh Ardabili, Ardabil, Iran. ${ }^{2}$ Islamic Azad University, Tabriz Branch, Faculty of Literature and

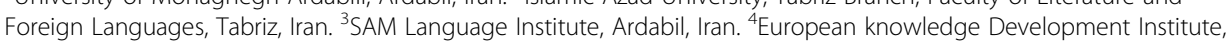
Ankara, Turkey.

Received: 20 April 2020 Accepted: 16 July 2020

Published online: 27 July 2020

\section{References}

Bahrouni, F., \& Tuzlukova, V. (2019). Investigating teachers and students' perceptions of written corrective feedback in the context of tertiary education in Oman. Language Testing in Focus, 1, 1-17.

Berg, E. C. (1999). The effects of trained peer response on ESL students' revision types and writing quality. Journal of Second Language Writing, 8(3), 215-241.

Bitchener, J., \& Knoch, U. (2009). The value of a focused approach to written corrective feedback. ELT Journal, 63(3), 204-211.

Bitchener, J., \& Knoch, U. (2010). Raising the linguistic accuracy level of advanced L2 writers with written corrective feedback. Journal of Second Language Writing, 19, 207-217.

Byrd, D. R. (2003). Practical tips for implementing peer editing tasks in the foreign language classroom. Foreign Language Annals, 36(3), 434-441.

Chaudron, C. (1984). The effects of feedback on students' composition revisions. RELC Journal, 15, 1-15.

Chong, I. (2017). How students' ability levels influence the relevance and accuracy of their feedback to peers: A case study. Assessing Writing, 31, 13-23.

Diab, N. M. (2010). Effects of peer-versus self-editing on students' revision of language errors in revised drafts. System, 38, 85-95.

Ferris, D. R. (1995). Student reactions to teacher response in multiple-draft composition classrooms. TESOL Quarterly, 29(1), 33-53.

Ferris, D. R. (2003). Response to students writing: Implications for second language students. Mahwah: Lawrence Erlbaum.

Ferris, D. R. (2004). The "grammar correction" debate in L2 writing: Where are we, and where do we go from here? (and what do we do in the meantime ... .?). Journal of Second Lanquage Writing, 13, 49-62.

Foster, P., \& Skehan, P. (1996). The influence of planning and task type on second language performance. Studies in Second Language Acquisition, 18, 299-323.

Hu, G. (2005). Using peer review with Chinese ESL student writers. Language Teaching Research, 9(3), 321-342.

Hu, G., \& Lam, S. T. E. (2010). Issues of cultural appropriateness and pedagogical efficacy: Exploring peer review in a second language writing class. Instructional Science, 38, 371-394.

Hughes, A. (2003). Testing for language teachers. Cambridge: Cambridge University Press.

Hulstijn, J. H., \& Laufer, B. (2001). Some empirical evidence for the involvement load hypothesis in vocabulary acquisition. Language Learning, 51, 539-558.

Hyland, F. (2000). ESL writers and feedback: Giving more autonomy to students. Language Teaching Research, 4(1), 33-54.

Hyland, F. (2010). Future directions in feedback on second language writing: Overview and research agenda. International Journal of English studies, 10(2), 171-182.

Karim, K., \& Endley, M. J. (2019). Should feedback be direct or indirect? Comparing the effectiveness of different types of WCF on L1 Arabic writers' use of English prepositions. Lanquage Teaching Research Quarterly, 13, 68-84.

Keen, J. (2010). Strategic revisions in the writing of year 7 students in the UK. Curriculum Journal, 21(3), 255-280. 
Kim, H. R., \& Bowles, M. (2019). How deeply do second language learners process written corrective feedback? Insights gained from think-Alouds. TESOL Quarterly, 53(4), 913-938.

Kozlova, I. (2010). Ellis's corrective feedback in a problem-solving context. ELT Journal, 64(1), 95-97.

Lee, I. (2009). Ten mismatches between teachers' beliefs and written feedback practice. ELT Journal, 63(1), 13-22.

Lee, I. (2011). Feedback revolution: What gets in the way? ELT Journal, 65(1), 1-12.

Liu, J., \& Sadler, R. W. (2003). The effect and affect of peer review in electronic versus traditional modes on L2 writing. Journal of English for Academic Purposes, 2, 193-227.

Lundstorm, K., \& Baker, W. (2009). To give is better than to receive: The benefits of peer review to the reviewers' own writing. Journal of Second Language Writing, 18, 30-43.

Ma, J. (2010). Chinese EFL learners' decision-making while evaluating peers' texts. International Journal of English studies, 10(2), 99-120.

Mahfoodh, O. H. A. (2017). "I feel disappointed": EFL university students' emotional responses towards teacher written feedback. Assessing Writing, 31, 53-72

Miao, Y., Badger, R., \& Zhen, Y. (2006). A comparative study of peer and teacher feedback in a Chinese EFL writing class. Journal of Second Language Writing, 15, 179-200

Min, H. T. (2006). The effects of trained peer review on EFL students' revision types and writing quality. Journal of Second Language Writing, 15, 118-141.

Moon, J. (2008). L2 children and writing: A neglected skill? ELT Journal, 62(4), 398-400.

Motallebzadeh, K., Kondori, A., \& Kazemi, S. (2020). The effect of peer feedback on EFL learners' classroom anxiety. Language Teaching Research Quarterly, 18, 40-52.

Muncie, J. (2000). Using written teacher feedback in EFL composition classes. ELT Journal, 54(1), 47-53.

Nelson, G. L., \& Carson, J. G. (1998). ESL students' perceptions of effectiveness in peer response groups. Journal of Second Language Writing, 7(2), 113-131.

Nemati, M., Alavi, S. M., \& Mohebbi, H. (2019). Assessing the effect of focused direct and focused indirect written corrective feedback on explicit and implicit knowledge of language learners. Language Testing in Asia, 9(1), 7.

Nemati, M., Alavi, S. M., Mohebbi, H., \& Masjedlou, A. P. (2017). Speaking out on behalf of the voiceless learners: Written corrective feedback for English language learners in Iran. Issues in Educational Research, 27(4), 822.

Paulus, T. M. (1999). The effect of peer and teacher feedback on student writing. Journal of Second Language Writing, 8(3), 265-289.

Peterson, S. S., \& McClay, J. (2010). Assessing and providing feedback for student writing in Canadian classrooms. Assessing Writing, 15, 86-99

Peterson, S. S., \& Portier, C. (2014). Grade one peer and teacher feedback on student writing. Education 3-13: International Journal of Primary, Elementary and Early Years Education, 42(3), 237-257.

Pham, V. P. H., Huyen, L. H., \& Nguyen, M. T. (2020). The incorporation of qualified peer feedback into writing revision. The Asian Journal of Applied Linguistics, 7(1), 45-59.

Raza, K. (2019). Learner preferences for teacher corrective feedback: A survey study of Arab students from Qatar. Language Teaching Research Quarterly, 11, 43-53.

Reichelt, M. (2019). Contextual factors impacting feedback practices for non-English L2 writing. Foreign Language Annals, 52(4), 744-752.

Reinders, H., \& Mohebbi, H. (2018). Written corrective feedback: The road ahead. Language Teaching Research Quarterly, 6, 1-6.

Sánchez-Naranjo, J. (2019). Peer review and training: Pathways to quality and value in second language writing. Foreign Language Annals, 52(3), 612-643.

Suzuki, M. (2008). Japanese learners' self revisions and peer revisions of their written compositions in English. TESOL Quarterly, 42(2), 209-233.

Truscott, J. (2004). Evidence and conjecture on the effects of correction: A response to Chandler. Journal of Second Language Writing, 13, 337-343

Tsui, A. B. M., \& Ng, M. (2000). Do secondary L2 writers benefit from peer comments? Journal of Second Language Writing, 9 , $147-170$.

Villamil, O. S., \& De Guerrero, M. (1996). Peer revision in the L2 classroom: Social-cognitive activities, mediating strategies, and aspects of social behavior. Journal of Second Language Writing, 5, 51-75.

Villamil, O. S., \& De Guerrero, M. (1998). Assessing the impact of peer revision on L2 writing. Applied Linguistics, 19(4), 491-514.

Wigglesworth, G., \& Storch, N. (2009). Pair versus individual writing: Effects on fluency, complexity and accuracy. Language Testing, 26(3), 445-466.

Wu, Y., \& Schunn, C. D. (2020). From feedback to revisions: Effects of feedback features and perceptions. Contemporary Educational Psychology, 60, 101826

Yu, S., \& Hu, G. (2017). Understanding university students' peer feedback practices in EFL writing: Insights from a case study. Assessing Writing, 33, 25-35.

Yu, S., \& Lee, I. (2016). Peer feedback in second language writing (2005-2014). Language Teaching, 49(4), 461-493.

Zhang, X., \& McEneaney, J. E. (2020). What is the influence of peer feedback and author response on Chinese University students' English writing performance? Reading Research Quarterly, 55(1), 123-146.

Zhang, Z. V. (2020). Engaging with automated writing evaluation (AWE) feedback on L2 writing: Student perceptions and revisions. Assessing Writing, 43, 1-14.

Zhu, W. (2001). Interaction and feedback in mixed peer response groups. Journal of Second Language Writing, 10, 251-276.

\section{Publisher's Note}

Springer Nature remains neutral with regard to jurisdictional claims in published maps and institutional affiliations. 